\title{
FURFURAL - DA BIOMASSA AO LABORATÓRIO DE QUÍMICA ORGÂNICA
}

\author{
Paulo Roberto Ribeiro, José Roque Mota Carvalho e Regina Geris* \\ Instituto de Química, Universidade Federal da Bahia, Campus de Ondina, Rua Barão de Geremoabo, s/n, 40170-290 Salvador - \\ BA, Brasil \\ Vinícius Queiroz e Miguel Fascio \\ União Metropolitana de Educação e Cultura S/C Ltda, Av. Luiz Tarquínio Pontes, 600, 42700-000 Lauro de Freitas - BA, Brasil
}

Recebido em 21/7/11; aceito em 25/11/11; publicado na web em 31/1/12

\begin{abstract}
FURFURAL - FROM BIOMASS TO ORGANIC CHEMISTRY LABORATORY. The goal of this manuscript is provide to students of Chemistry and related areas an alternative experiment in which they can obtain a compound and learn to observe and interpret properties and predict organic structure by obtaining furfural from biomass. Furfural is an organic compound, obtained through acid hydrolysis of pentosans, commonly used in the chemical and pharmaceutical industries. Students are guided to get furfural through extractive procedures and chemical reactions adapted to semi-micro laboratory scale. Characterization of furfural was done by chemical tests and physical properties. Identification was accomplished by a series of spectroscopic and spectrometric techniques.
\end{abstract}

Keywords: furfural; biomass; experimental organic chemistry.

\section{INTRODUÇÃO}

Em disciplinas de Química Orgânica Experimental os alunos são levados a aprender a trabalhar com substâncias orgânicas através da obtenção, caracterização, identificação e transformação destas. Os compostos podem ser extraídos a partir de fontes naturais ou sintetizados utilizando outras substâncias químicas como materiais de partida. O material obtido - extrato bruto ou produto da reação deve passar por procedimentos de separação e/ou purificação com o intuito de se obter a substância química de interesse, a qual deve ser, em seguida, caracterizada e identificada. ${ }^{1}$

O objetivo deste manuscrito foi propor uma nova atividade laboratorial em disciplinas de Química Orgânica Experimental envolvendo o aproveitamento da biomassa, através da obtenção de furfural a partir de espigas de milho verde. A atividade proposta envolve várias metodologias e técnicas analíticas ensinadas nas aulas práticas de Química Orgânica, entre elas destilação por arraste a vapor, destilação à pressão reduzida, extração com solventes quimicamente inertes, cromatografia em camada delgada, testes químicos para identificação de grupos funcionais, cromatografia gasosa acoplada à espectrometria de massas, espectroscopia nas regiões do ultravioleta e infravermelho e ressonância magnética nuclear de ${ }^{1} \mathrm{H} \mathrm{e}{ }^{13} \mathrm{C}$. Este experimento, perfeitamente executável em laboratórios de ensino do nível superior, tem a vantagem de apresentar ao aluno um trabalho integral que vai da fonte da matéria orgânica à obtenção de um produto que é utilizado como matéria-prima nas indústrias química e farmacêutica; além disto, a aplicação de diferentes técnicas e métodos analíticos tem por finalidade conduzir os alunos à observação, interpretação e predição de estruturas de compostos orgânicos através de suas propriedades.

\section{BIOMASSA}

O final do século XX presenciou o crescimento da conscientização da sociedade em relação à degradação do meio ambiente, ${ }^{2}$ levando à busca por processos de reciclagem, bem como à utilização de resíduos descartados da biomassa. ${ }^{3}$ A utilização da biomassa vem crescendo mundialmente como fonte renovável para a produção

\footnotetext{
*e-mail: rmgeris@ufba.br
}

de energia elétrica e de biocombustíveis (etanol, biodiesel, biogás, etc).$^{3-5}$ Ademais, a biomassa se destaca como uma fonte de material de partida na produção de diversas substâncias orgânicas que servirão como insumos nos mais variados processos industriais.

O termo biomassa é empregado para descrever matéria orgânica existente nos organismos. ${ }^{6}$ A biomassa de origem vegetal é produzida via fotossíntese, um processo no qual os vegetais convertem $\mathrm{CO}_{2}$ do ar e moléculas de água, na presença de luz solar, em grandes blocos de construção da matéria, os carboidratos, sendo as glicanas e as hemiceluloses os polissacarídeos de maior importância. ${ }^{4}$ Entre as glicanas, que são homopolissacarídeos constituídos de unidades monoméricas de $D$-glicopiranoses, o amido e a celulose estão entre os mais abundantes $;^{7}$ a diferença estrutural entre estes dois biopolímeros está no tipo de ligação glicosídica que formam, respectivamente, ligações tipo $\alpha 1 \rightarrow 4$ e $\beta 1 \rightarrow 4$, como mostra a Figura 1..$^{7}$ Ambos são encontrados nas células vegetais, com diferentes funções: o amido é um polissacarídeo de reserva, abundante nos tubérculos, raízes e sementes, enquanto que a celulose é o componente estrutural da parede celular. ${ }^{8}$ Por outro lado, as hemiceluloses são polímeros complexos de homo ou heteropolissacarídeos ramificados, sendo formadas principalmente pelas aldopentoses xilose e arabinose, pelas aldo-hexoses glicose e manose e pelos ácidos metilglicurônico e galacturônico, ${ }^{4}$ não possuindo, portanto, nenhuma relação estrutural com a celulose (Figura 1).

\section{Furfural e seus derivados}

A hidrólise ácida de celulose e de pentosanas (xilanas, arabinanas e poliuronídeos) encontradas em plantas e materiais residuais resulta na produção de hidroximetilfurfural e furfural, respectivamente. ${ }^{9}$

Furfural (1), de fórmula molecular $\mathrm{C}_{5} \mathrm{H}_{4} \mathrm{O}_{2}$, é um óleo límpido e incolor que quando exposto ao oxigênio do ar sofre oxidação tornando-se castanho-avermelhado. ${ }^{10}$ Este aldeído heterocíclico e aromático é conhecido também como 2-furanocarboxialdeído, furaldeído, 2-furanaldeído, fural e furfuraldeído.

A produção mundial de furfural é de 250.000 t/ano, sendo diretamente utilizada como solvente ou como material de partida para a preparação de outros solventes orgânicos, como o álcool furfurílico (2) e o tetra-hidrofurano (THF, 3). ${ }^{10-12} \mathrm{O}$ álcool furfurílico (2) é 


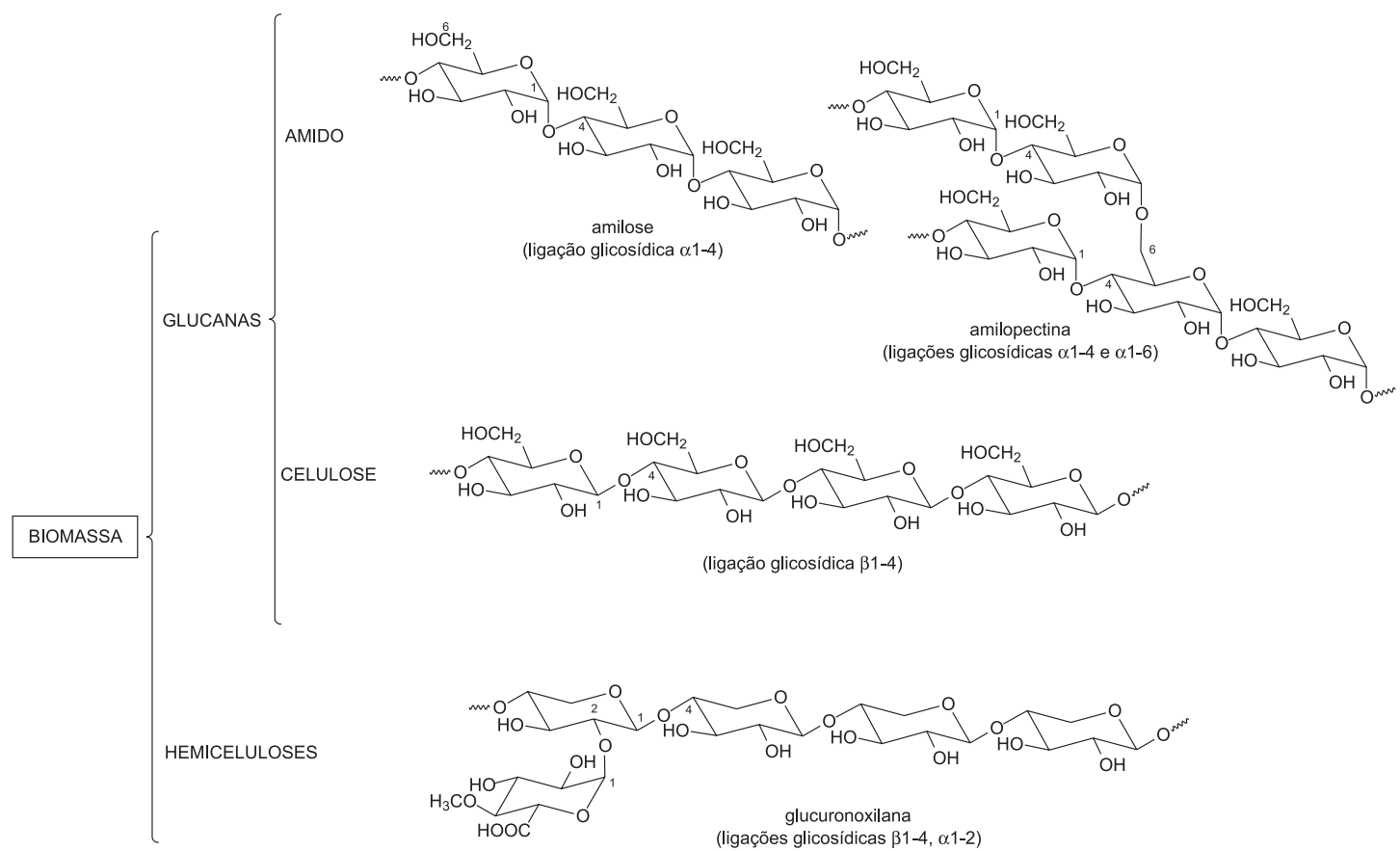

Figura 1. Representação estrutural parcial dos principais polissacarídeos presentes na biomassa

diretamente preparado pela hidrogenação catalítica do furfural e apresenta uma série de aplicações na indústria química, tais como, material de partida na produção do álcool tetra-hidrofurfurílico (4), na manufatura de resinas e como intermediário na produção de fragrâncias e vitamina C. ${ }^{10,13}$ THF (3) é um importante solvente industrial obtido através da hidrogenação do furano (5) que, por sua vez, é obtido por descarbonilação catalítica do furfural (1). ${ }^{13}$

Outros importantes derivados são a furfurilamina (6), ácido furoico (7) e ácido levulínico (8) (Esquema 1). A furfurilamina (6) é utilizada na produção de substâncias com atividades farmacológica e pesticida, bem como no processo de produção de fibras, sendo preparada via aminação redutiva do furfural. ${ }^{13} \mathrm{O}$ ácido furoico (7) é utilizado na síntese de medicamentos e de perfumes; o ácido levulínico (ácido 4-oxo-pentanoico, 8) é um importante intermediário para a síntese de ácido succínico (9) que é usado como aditivo alimentar e na síntese de produtos farmacêuticos; o ácido $\delta$-aminolevulínico (10) é um excelente herbicida, inseticida e regulador do crescimento de plantas. ${ }^{9,13}$

A principal vantagem do furfural como matéria-prima, é que suas fontes são renováveis. Os resíduos agrícolas, tais como sabugo de milho, bagaço de cana-de-açúcar, casca de arroz e farelo de trigo, gerados em grandes quantidades no Brasil, são as principais fontes utilizadas para a obtenção do furfural, uma vez que são ricas em hemicelulose e estão regularmente disponíveis em grandes quantidades. ${ }^{11,12}$ Bagaço de cana-de-açúcar e sabugos de milho são os dois materiais mais comumente utilizados para a produção de furfural (contendo 25

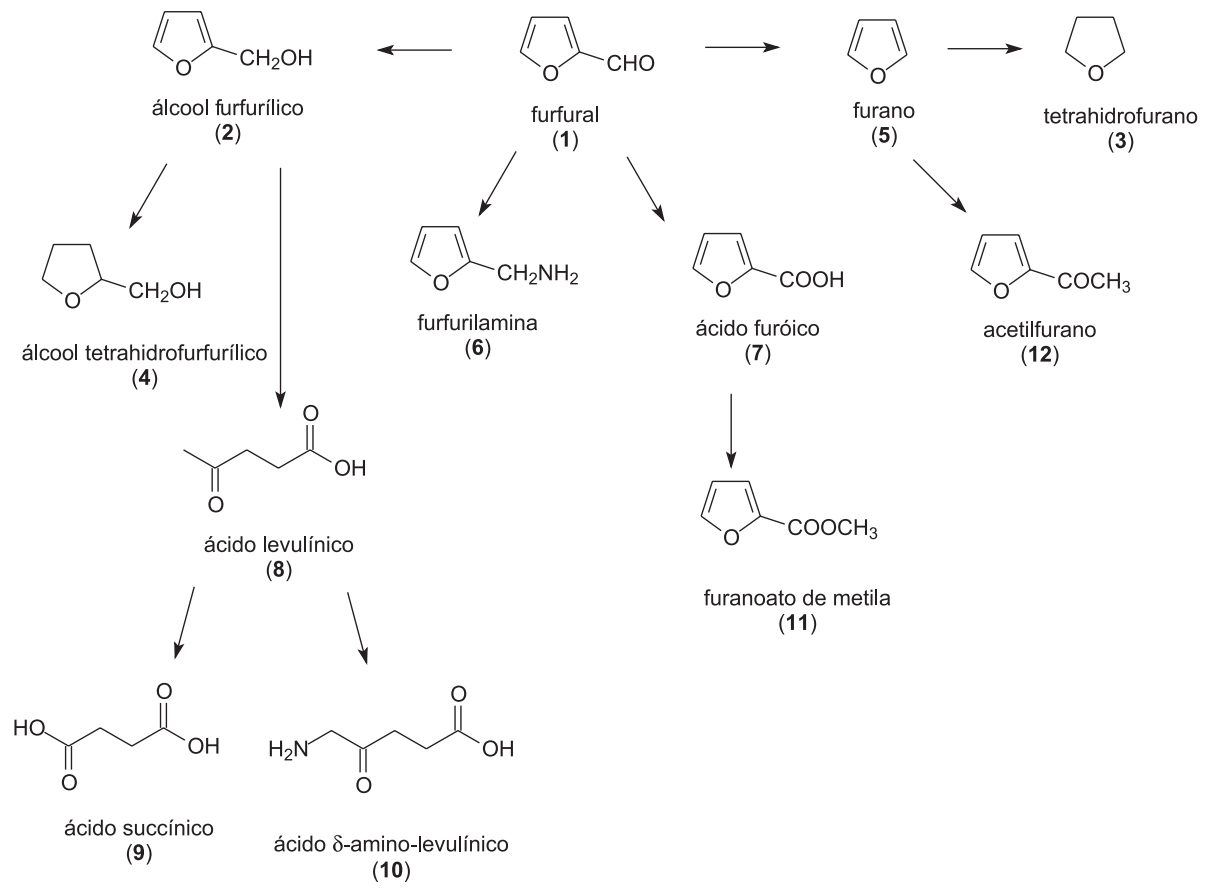

Esquema 1. Produtos ou intermediários de interesse derivados do furfural 
e 35\% de pentosanas, respectivamente), sendo responsáveis por mais de $98 \%$ de todo o furfural produzido. ${ }^{10}$ Vale ressaltar que a China é considerada o maior produtor desta substância (cerca de 70\%), utilizando como matéria-prima principal o sabugo do milho. ${ }^{10,11}$

\section{PARTE EXPERIMENTAL}

\section{Material vegetal}

Sabugos de milho.

\section{Reagentes e equipamentos}

Reagentes: ácido clorídrico (Quimex); sulfato de sódio anidro (Quimex); clorofórmio PA (Quimex); clorofórmio deuterado (Cambridge Isotope Laboratories, Inc); gel de sílica (Merck), 2,4-dinitrofenil-hidrazina (RP, Carlo Erba do Brasil Ltda.); nitrato de prata (Avi-Cenna); hidróxido de amônio (Merck).

Equipamentos: cromatógrafo gasoso acoplado ao espectrômetro de massas (CG-EM) Varian 1200 CP 3800 com detector quadrupolo 1200 L; bomba de vácuo (Marconi Modelo MA 053/4); evaporador rotativo Laborota 4000; refratômetro (Quimis Q767-B); espectrômetro na região do infravermelho Bomem 102; espectrofotômetro na região UV-VIS (UV/VIS Spectrophotometer Mini 1240 Shimadzu); espectrômetro de RMN Bruker (AMX 500 Avence).

\section{Hidrodestilação}

Em um balão $(500 \mathrm{~mL})$ foram adicionados $25 \mathrm{~g}$ do sabugo de milho triturado e $200 \mathrm{~mL}$ da solução de ácido clorídrico $6 \mathrm{~mol} \mathrm{~L}{ }^{-1}$. O balão foi então acoplado a um sistema de destilação simples, previamente montado como indicado na literatura. ${ }^{14}$ Esse material foi aquecido registrando-se a temperatura na qual as primeiras gotas do hidrodestilado foram coletadas. A hidrodestilação foi monitorada a cada 15 min, utilizando-se o ensaio com a 2,4-dinitrofenil-hidrazina, e prosseguiu até que não fosse mais observada a formação de um precipitado vermelho (aproximadamente $2 \mathrm{~h}$ ). Foram coletados 150 $\mathrm{mL}$ de volume do hidrodestilado.

\section{Extração e purificação do furfural}

Posteriormente, o hidrodestilado foi transferido para um funil de separação e o produto de interesse foi obtido por extração líquido-líquido, utilizando-se $40 \mathrm{~mL}$ de diclorometano como solvente extrator (o diclorometano pode ser substituído pelo clorofórmio ou acetato de etila). A fase orgânica foi recolhida em um frasco de Erlenmeyer. Este procedimento de extração foi repetido por mais duas vezes para garantir uma transferência completa da substância de interesse, devido ao coeficiente de distribuição. ${ }^{15} \mathrm{~A}$ água residual na fase orgânica foi removida com sulfato de sódio anidro. A fase orgânica foi colocada num balão de fundo redondo e o solvente removido à pressão reduzida com o auxílio do evaporador rotatório. O resíduo do balão foi então submetido à destilação sob pressão reduzida em uma temperatura de ebulição de $106{ }^{\circ} \mathrm{C}$ a $360 \mathrm{mmHg}$ e o valor do índice de refração do líquido obtido foi aferido a uma temperatura de $25^{\circ} \mathrm{C}$.

\section{Condições de análise do furfural}

O produto purificado foi analisado qualitativamente através de cromatografia em camada delgada (CCD), testes químicos para identificação de grupos funcionais orgânicos e métodos espectroscópicos de análise de compostos orgânicos.

O material foi reavaliado através da reação com 2,4-dinitrofenil- hidrazina. O reagente de Tollens (solução amoniacal de nitrato de prata) foi utilizado para distinguir aldeídos de cetonas pela formação de um espelho de prata no tubo de reação, e o teste de chama (ensaio de pirólise) para verificar a presença de cadeias hidrocarbônicas alifáticas ou aromáticas. ${ }^{14}$ Vale ressaltar que o procedimento das técnicas supracitadas encontra-se descrito nos livros de Química Orgânica Experimental.

A análise por CCD foi realizada dissolvendo-se o produto em clorofórmio e aplicação desta solução sobre uma placa de vidro contendo gel de sílica como fase estacionária. Foi utilizada como fase móvel uma mistura ternária de hexano:acetato de etila:ácido acético (85:14:1). Após a eluição a cromatoplaca foi revelada em uma câmara de radiação ultravioleta e em uma cuba com vapores de iodo.

O cromatograma de íons totais foi obtido através da injeção de um volume de $1 \mu \mathrm{L}$ da amostra dissolvida em clorofórmio em um cromatógrafo a gás, utilizando-se uma coluna Factofour VF1 ms, 60 m de comprimento e uma espessura de $0,32 \mathrm{~mm}$ e hélio como gás de arraste. A programação de temperatura utilizada foi a seguinte: 5 min a uma temperatura de $40^{\circ} \mathrm{C}$, seguida de aumento de temperatura para $90{ }^{\circ} \mathrm{C}$ a uma taxa de $6,0^{\circ} \mathrm{C} / \mathrm{min}$; em sequência, um aumento de temperatura para $180^{\circ} \mathrm{C}$ a uma taxa de $10,0^{\circ} \mathrm{C} / \mathrm{min}$, chegando numa temperatura final de $270{ }^{\circ} \mathrm{C}$ a uma taxa de $20,0^{\circ} \mathrm{C} / \mathrm{min}$ (tempo total de $32 \mathrm{~min}$ ). O espectro de massas foi obtido por ionização por impacto eletrônico, aplicando-se uma energia de colisão de 70 eV.

O espectro na região do infravermelho (IV) foi obtido em filme com janela de $\mathrm{NaCl}$ e o espectro na região do UV/VIS foi obtido preparando-se uma solução contendo a substância em uma concentração de 2 ppm e o registro do comprimento de onda máximo foi realizado variando-se o comprimento de onda entre 200 a $400 \mathrm{~nm}$. Os dados de RMN ${ }^{1} \mathrm{H}$ e ${ }^{13} \mathrm{C}$ foram obtidos utilizando-se clorofórmio deuterado como solvente e tetrametilsilano como padrão interno de referência.

\section{RESULTADOS E DISCUSSÃO}

Um líquido de aspecto límpido e incolor, com índice de refração igual a 1,5191 a $25^{\circ} \mathrm{C}$ foi obtido quando do uso da destilação à pressão reduzida, em um rendimento de 6 a $7 \%$ ( 6 a $7 \mathrm{~g}$ de produto por $100 \mathrm{~g}$ de sabugo de milho fresco), nas condições experimentais aplicadas. Na reação de hidrólise das pentosanas foi utilizado ácido clorídrico como catalisador da reação, embora na obtenção do furfural comercial os catalisadores mais empregados sejam os ácidos sulfúrico ou fosfórico sob temperaturas elevadas. ${ }^{13} \mathrm{~A}$ escolha do ácido clorídrico ocorreu durante a etapa de otimização da metodologia, por apresentar um maior rendimento do material extraído.

A presença de uma mancha única com valor de $\mathrm{Rf}$ de 0,44 no sistema de eluição empregado sugeriu um elevado grau de pureza do produto. A formação de um precipitado vermelho no teste com 2,4-dinitrofenil-hidrazina, do espelho de prata no tubo contendo a amostra com o reagente de Tollens e a formação de fuligem no teste de chama permitiram caracterizar este produto como um aldeído aromático.

Em seguida, o material foi analisado por CG-EM e a presença de um pico único com tempo de retenção de 18,56 min foi detectado no cromatograma de íons totais. O espectro de massas apresentou o pico do íon molecular $\left(\mathrm{M}^{+}\right.$) em $\mathrm{m} / \mathrm{z}, 96$ (55\%), compatível com a fórmula molecular $\mathrm{C}_{5} \mathrm{H}_{4} \mathrm{O}_{2}$ (Figura $1 \mathrm{~S}$, material suplementar). O espectro na região do IV (Figura $2 \mathrm{~S}$, material suplementar) exibiu bandas em $3140,2720,2810$ e $1700 \mathrm{~cm}^{-1}$, sugerindo a presença de uma carbonila de aldeído aromático. O espectro na região do UV/VIS apresentou duas bandas de absorção: em $230 \mathrm{~nm}$, de menor intensidade, que corresponde a uma transição $n \rightarrow \pi *$ de grupos carbonílicos, e em 275 $\mathrm{nm}$, de maior intensidade, que corresponde a uma transição $\pi \rightarrow \pi^{*}$ de sistemas aromáticos. 


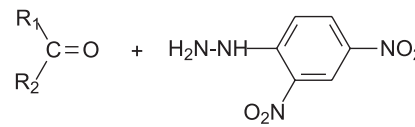

aldeído ou cetona 2,4-dinitrofenilhidrazina<smiles>[R]C(=NNc1ccc([N+](=O)[O-])cc1[N+](=O)[O-])C([R])C</smiles>

2,4-dinitrofenilhidrazona (sólido amarelo-avermelhado)

b) Teste de Tollens

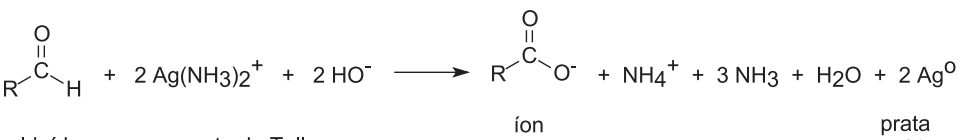

$$
\begin{aligned}
& \text { aldeído reagente de Tollens } \quad \begin{array}{cc}
\text { íon } \\
\text { carboxilato }
\end{array}
\end{aligned}
$$

Figura 2. Equações das reações dos testes de caracterização do grupo funcional aldeído

O espectro de $\mathrm{RMN}{ }^{1} \mathrm{H}$ apresenta quatro sinais em $\delta 6,64$ (dd, $J$ $=3,6 ; 1,6), 7,32(\mathrm{dd}, J=3,6 ; 0,8), 7,75(\mathrm{dt}, J=1,6 ; 0,8 ; 0,8)$ e 9,67 $(\mathrm{d}, J=0,8)$ (Figura 3S, material suplementar). A análise dos deslocamentos químicos e das intensidades dos sinais e das constantes de acoplamentos entre os núcleos de hidrogênio aponta para um sistema aromático contendo o anel furânico $\alpha$-substituído e para a presença de um grupo carbonílico de aldeído. O espectro de $\mathrm{RMN}{ }^{13} \mathrm{C}$ apresentou cinco sinais que podem ser facilmente identificados como os carbonos do furfural pela análise dos deslocamentos químicos $(\delta 112,8,121,8$, $148,4,152,9$ e 177,9 (Figura 4S, material suplementar).

Este experimento visa também o propósito de iniciar o estudante na identificação de substâncias e na determinação de estruturas moleculares. Desta forma, é apresentada uma discussão de estratégias que podem ser seguidas pelos estudantes, que levam não só à caracterização, mas também à identificação ou determinação estrutural de substâncias. A determinação da estrutura pode ser solicitada quando não se consegue identificar a substância. Vale ressaltar que uma discussão detalhada e estruturalmente justificada dos dados espectrais de IV, UV, RMN e EM deve ser solicitada pelo professor.

Deste modo, uma vez obtido o material com elevado grau de pureza, o primeiro passo dado pelo estudante foi a realização dos procedimentos preliminares de caracterização do mesmo. O líquido obtido reagiu imediatamente com 2,4-dinitrofenil-hidrazina, com formação do derivado 2,4-dinitrofenil-furfural-hidrazona. Os aldeídos e cetonas reagem com 2,4-dinitrofenil-hidrazina, sob condições ácidas, para dar derivados de 2,4-dinitrofenilidrazona que são sólidos de coloração entre amarelo a vermelho (Figura 2). ${ }^{1,14}$ A formação de um espelho de prata no tubo contendo a amostra e o reagente de Tollens confirma a presença do aldeído, que é oxidado para o carboxilato correspondente com deposição da prata metálica nas paredes do tubo. As cetonas não são oxidadas nas mesmas condições, necessitando de condições mais drásticas para ruptura da ligação C-C. ${ }^{1}$ Estes resultados, somados ao teste de chama com formação de fuligem, que é sugestivo da presença de compostos aromáticos que sendo mais estáveis requerem mais energia para a combustão completa, indicaram que o produto obtido da hidrólise ácida da espiga de milho verde se trata de um aldeído aromático.

A análise dos sinais do espectro na região do IV confirmou as indicações das análises químicas; por esta razão este espectro, hoje, as substitui. A interpretação dos dados obtidos por RMN de ${ }^{1} \mathrm{H}$ foi recomendada durante o processo de identificação do furfural, enfatizando na relação dos sinais à estrutura e a aparência dos mesmos nos espectros. Por exemplo, o quintupleto atribuído ao $\mathrm{H} \alpha^{\prime}$ do anel furânico que acopla com todos os prótons da molécula, inclusive com o da função aldeído, é uma excelente situação para a discussão de alguns fenômenos da ressonância magnética nuclear de ${ }^{1} \mathrm{H}$.
A partir dos sinais observados no espectro de massas para o furfural foi possível sugerir a proposta de fragmentação discutida aqui em função da dificuldade de interpretação deste tipo de espectro (Esquema 2). O pico base do espectro em $\mathrm{m} / \mathrm{z} 95$ indica a perda do radical hidrogênio, uma clivagem alfa característica em espectros de massas de aldeídos, seguido de duas perdas consecutivas de monóxido de carbono com formação dos picos em $m / z 67$ (10\%) e 39 (47\%), este último de maior intensidade por resultar em um cátion ciclopropênico.

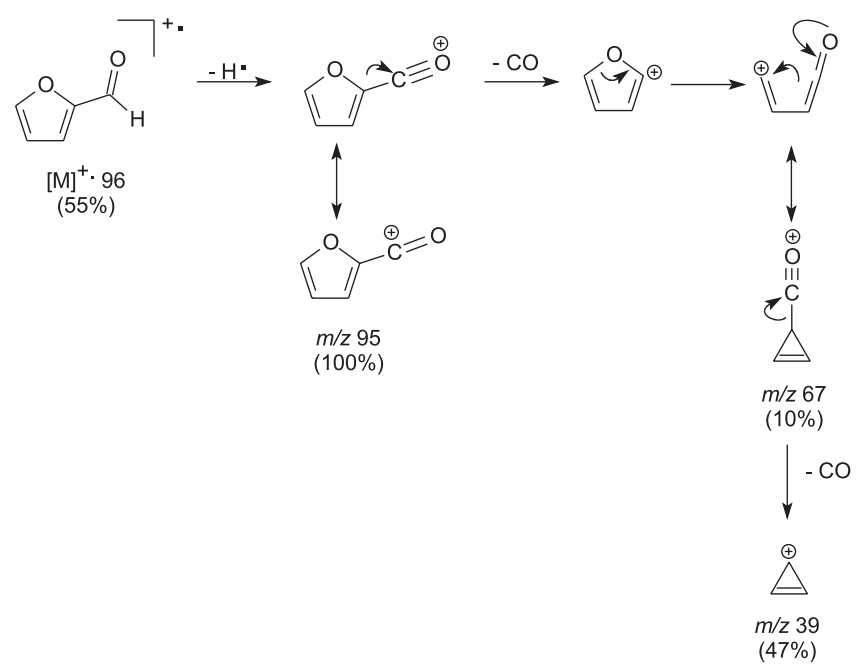

Esquema 2. Proposta de fragmentação para o furfural

Por fim, a hidrólise de pentosanas (I) catalisada por ácido para a obtenção do furfural (1) pode ser proposta, iniciando-se com a protonação do oxigênio glicosídico das mesmas (II). A ligação C-O do ácido conjugado protonado é rompida para formar o íon oxônio (III). Ocorre então uma rápida adição de água (IV) seguida de transferência de hidrogênio (prototropismo, PT) para a obtenção do monômero livre, que se encontra em equilíbrio entre a forma hemiacetálica cíclica (V) e a forma em cadeia aberta (VI), esta última em menor proporção. A protonação do grupo hidroxílico em C-3 (VII) leva à formação do intermediário enólico (VIII), que por sua vez é convertido no intermediário 4,5-di-hidroxi-2-oxo-pentanal protonado (IX). A adição nucleofílica intramolecular do grupo hidroxílico em C-5 no carbono C-2 leva à formação do hemiacetal (X). O furfural (1) é formado após a perda de duas moléculas de água, conforme mostra o Esquema 3.

Este procedimento simples de obtenção do furfural a partir da biomassa pode ser conduzido em um laboratório experimental de Química em, no máximo, 12 h (2 aulas práticas de 6 h): na primeira 


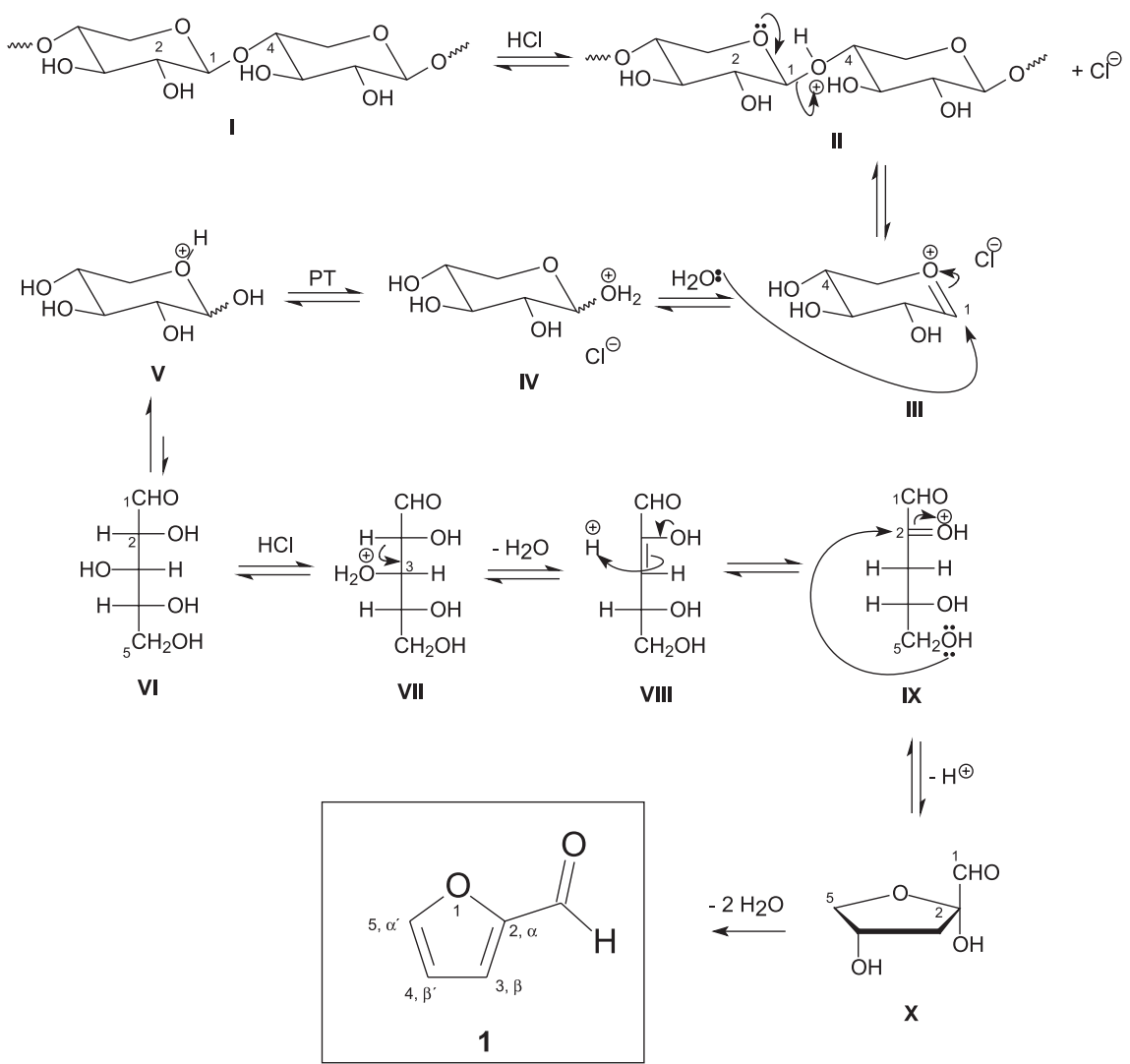

Esquema 3. Proposta de mecanismo para a formação de furfural a partir da hidrólise ácida de pentosanas

aula, os alunos podem obter o furfural com alto grau de pureza e, em seguida, coletar os dados físicos e realizar as reações de caracterização. Os espectros podem ser obtidos no período que antecede a próxima aula, para então o professor conduzir a discussão dos dados e as etapas que deveriam ser seguidas para caracterizar e identificar uma substância orgânica.

Esta proposta de aula prática foi aplicada às turmas de Química Orgânica Experimental III (QUI A64) durante os semestres 2009.2 e 2010.1 e alguns questionamentos foram colocados para discussão entre os alunos, tais como, o mecanismo da reação de formação do furfural e dos derivados utilizados para a caracterização do material; as técnicas envolvidas durante o experimento; as ferramentas de identificação de compostos orgânicos; a importância da utilização de biomassa como material de partida, bem como os conceitos de resíduo, rejeito e insumo; a aplicação do furfural e seus derivados nas indústrias química, farmacêutica e cosmética; a evolução das técnicas de caracterização dos compostos orgânicos e, a visão de empreendedorismo.

\section{CONCLUSÕES}

Uma das maneiras de despertar o interesse dos estudantes nas disciplinas experimentais é buscar informações sobre temas da atualidade e relacioná-los com ferramentas e técnicas usadas na academia. Uma motivação maior leva, consequentemente, a um maior envolvimento nas discussões e melhora a aprendizagem. Deste modo, um experimento de obtenção de furfural a partir da biomassa foi proposto, otimizado e posteriormente aplicado aos alunos de graduação em Química que cursavam a disciplina de Química Orgânica Experimental (QUI A64). A sequência das discussões foi ordenada de modo a conduzir o aluno a utilizar todas as ferramentas possíveis para caracterizar e identificar o material obtido como furfural.

Além disso, os conceitos dos termos resíduo, insumo e rejeito também foram enfatizados, aproximando-os da linguagem utilizada na indústria, como também a constatação da possibilidade de transformação de resíduos em insumos de alto valor agregado. Outra abordagem foi levantada com os alunos como uma reflexão sobre percepção de oportunidade, possibilidades de inovação e, consequentemente, de terem seus próprios negócios.

\section{MATERIAL SUPLEMENTAR}

Está disponível gratuitamente em http://quimicanova.sbq.org. br na forma de arquivo PDF e apresenta as Figuras 1S, referente ao espectro de massas, $2 \mathrm{~S}$ referente ao espectro na região do infravermelho, $3 \mathrm{~S}$ referente ao espectro de $\mathrm{RMN}{ }^{1} \mathrm{H}$ e $4 \mathrm{~S}$ referente ao espectro de $\mathrm{RMN}{ }^{13} \mathrm{C}$ para o furfural.

\section{AGRADECIMENTOS}

Ao Prof. Dr. A. Barison (UFPR) pela realização dos espectros de Ressonância Magnética Nuclear, às técnicas I. A. Mota e D. A. de Souza (SENAI/CETIND) pela obtenção de cromatogramas e espectros de massas por CG-EM, ao Prof. Dr. F. G. Cruz por aplicar essa proposta de aula prática em sua disciplina Química Orgânica Experimental III - QUI A64, durante os semestres 2009.2 e 2010.1 e à Profa. Dra. N. F. Roque pelas valiosas críticas e contribuição nas discussões. Os espectros não puderam ser realizados no IQ/UFBA em virtude dos espectrômetros estarem desativados em decorrência do incêndio ocorrido no IQ em março de 2009.

\section{REFERÊNCIAS}

1. Palleros, D. R.; Experimental Organic Chemistry, John Wiley \& Sons, Hoboken: New York, 2000.

2. van Bellen, H. M.; Ambiente \& Sociedade 2004, 7, 67. 
3. Spiro, T. G.; Stigliani, W. M.; Química Ambiental, $2^{\mathrm{a}}$ ed., Ed. Pearson Prentice Hall: São Paulo, 2009.

4. McKendry, P.; Bioresour. Technol. 2002, 83, 37.

5. Geris, R.; Santos, N. A. C.; Amaral, B. A.; Maia, I. S.; Castro, V. D.; Carvalho, J. R. M.; Quim. Nova 2007, 30, 1369.

6. Bracmort, K.; Gorte, R. W.; Congressional Research Service, 7-5700, R40529, 2010.

7. Cseke, L. J.; Kirakosyan, A.; Kaufman, P. B.; Warber, S. L.; Duke, J. A.: Brielmann, H. L.; Natural Products from Plants, $2^{\text {nd }}$ ed., CRC Press: Florida, 2006.

8. Lenhinger, A. L.; Nelson, D. L.; Cox, M. M.; Princípios de Bioquímica, $4^{a}$ ed., Editora Sarvier: São Paulo, 2007.

9. Hayes, D. J.; Ross, J.; Hayes, M. H. B.; Fitzpatrick, S. Em Biorefineries - Industrial Processes and Products; Kamm, B.; Gruber, V. R.; Kamm, M., eds.; Wiley-VCH: Weinheim, 2006, vol. 1, p. 139.
10. Win, D. T.; AU Journal of Technology 2005, 8, 185.

11. Wondu Business and Technology Services; Furfural Chemicals and Biofuels from Agriculture, Rural Industries Research and Development Corporation, 06/127, Sydney, 2006, 39.

12. Montané, D.; Salvadó, J.; Torras, C.; Farriol, X.; Biomass and Bioenergy 2002, 22, 295 .

13. Corma, A.; Iborra, S.; Velty, A.; Chem. Rev. 2007, 107, 2411.

14. Vogel, A. I.; Química Orgânica: Análise Orgânica Qualitativa, 3ª ed., Ao Livro Técnico S.A.: Rio de Janeiro, 1978.

15. Eaton, D. C.; Laboratoty Investigations in Organic Chemistry, McGrawHill Book Company: New York, 1989. 